\title{
Improvement of Cost Calculation in Constructions - Application of the Standard Cost Method
}

\author{
Adela BREUER, "Eftimie Murgu" University of Reşiţa, Romania \\ Mihaela LESCONI FRUMUŞANU, ”Eftimie Murgu” University of Reşiţa, Romania \\ Jeanina Biliana CIUREA, ”Eftimie Murgu" University of Reşița, Romania \\ Monica ROŞU, "Eftimie Murgu" University of Reşița, Romania
}

\begin{abstract}
Grace to the analysis of several commercial companies effectively performed "on the field", we could remark the necessity to change the method of cost calculation, our motivation being related to the simplification of calculations and the reduction of the labour volume, but especially the necessity to know in due time the deviations occurred as well as the causes having led to their apparition. The importance of knowing the deviations in due time results from the very basic characteristics of the constructions execution, i.e. the performance of works during several budgetary years, which leads to the modifications of prices and materials, the introduction of new technologies, and to the performance of open air activities, making the execution of constructions works be influenced by the atmospheric condition. But the most important aspect of knowing the deviations is the correct determination of expenses and their inscribing in the corresponding period, in view of determining the result of the budgetary year. Our proposal for the enhancement of the method of cost calculation in constructions is the application of the standard cost method in the variant "single standard cost".
\end{abstract}

\section{Keywords}

Construction works, cost calculation, standard cost

JEL Code:M11, M41

\section{Introduction}

The domain of constructions has always had a very important role in the development of national economy, Romania following the trend of the countries worldwide in this sector, i.e. of continual development and growth. In supporting our assertion we evoke the official statistic data showing us that, while in 2002 the weight of constructions in the total GDP was of 5.7\%, in 2008 it reached $10,5 \%$ of the total GDP ${ }^{1}$, and this happened in the context in which the trade had a weight of $23.3 \%$ in the total GDP in 2008 , and industry of $22.9 \%{ }^{2}$, and, taking into account the economic crisis, that affected the world economy and implicitly the Romanian economy, and led to the failure to reach the predicted data for the domain of constructions, i.e. 14-15\% of the total GDP. Nevertheless, for the year 2009 one predicted a level of $8-8.5 \%$ for the field of constructions in total $\mathrm{GDP}^{3}$, data that will probably inscribe again in the category of failures. At the level of the European Union the data regarding the sector of constructions is in similar bad shape, 2009 registering major declines in comparison with 2008, as for instance: Germany( $-25,6 \%, J a n u a r y)$, Slovenia (-22,8\%,April), Spain (-21,1\%, August). Romania had the steepest fall in the field of constructions in the entire European Union in August 2009, i.e. $-29 \%{ }^{4}$.

${ }^{1}$ www.insse.ro, 21.02 .2009$

2 www.sfin.ro , 21.02.2009

3 www.reportereconomic.ro , 20.02.2009

${ }^{4}$ www.epp.eurostat.ec.europa.eu , 17.02.2009 
The century of speed we live in, the economic crisis that affected the entire world economy, the general development of economic and social life, all triggered the search for and adaptation of the best solutions for the economic life, able to reduce the working time and costs, efforts concretised in the field of accounting by the development and enhancement of the calculation systems, attempt that led to the abandon of the calculation of effective costs, as they were replaced by planned costs, based on predictable consumption of materials and labour, evaluated at present prices or tariffs. By adopting these planned cost the system of cost calculation can reach its two important goals: the control of economic efficiency and the fundamenting of decisional processes.

\section{The improvement of the method of cost calculation in constructions}

Starting from the drawbacks of the classic method of cost calculation in constructions, in the attempt to improve the informational-accounting system in the construction companies, we shall seek a modern method of cost calculation able to respond to the needs of an economic entity in the conditions of Romanian and international market at the present moment.

The method we propose to be implemented in the construction companies is the standard cost method, its advantages compared to the classic method being the following:

- it allows the operative control of the consumption of the raw materials and labour, through the distinct and permanent follow up of deviations along the entire process of execution of construction works;

- it allows the performance of both the operative evidence and the accounting one, globally and by causes, from the moment of the apparition of batteries and until the moment of their distribution upon the final result.

The applicant of the standard - cost method presents the advantage of rationalising the accumulation work, as the unitary standard cost established in advance is considered real cost, as it is not necessary to calculate the effective cost at the end of each period of administration, the deviations being considered to be deviations form the normal and are passed directly upon results.

Another advantage of the standard - cost method is that, although it relies on the concept of total costs, classifying the expenses in direct expenditure and indirect expenditure, the method uses also the classification of expenses into variable and fixed expenses, which allows the analysis of costs in relation with the volume of production, but also the calculation of the indicators necessary for the adoption of certain scientifically fundament decisions.

From the three variants of application of the standard cost method, i.e. the partial standard cost variant, the single standard cost variant, and the double standard cost variant, we considered that the single standard cost variant is the most appropriate for the needs of the informational accounting system of the construction companies. The motivation of our choice results form the critics brought to the other two variants:

- the partial standard cost variant allows the establishment of the deviations from the accounting viewpoint only at the end of the administration period, which results in ignoring deviations during the execution of construction works, i.e. the causes having led to their occurrence. Another drawback of this variant is that the inventory of the works in course of execution at the end of the period involves a large volume of work; the double standard cost variant expresses the exceeding of consumption under the form of certain efficiency indicators that must me calculated, and not under the form of deviations. Then, the works under execution must be assessed at the end of the administration period both against standard cost and against effective cost. From the accounting viewpoint, the variant is extremely laborious as it implies the use of extra accounts for the registration of the standard production costs.

In comparison with the other two variants of the standard cost method, the single standard cost variant presents the following advantages:

- the works in course of execution directly results by means of registering consumptions and 
execution works in the accounts of calculation at standard cost, eliminating thus the large volume of work triggered by the inventorying of the works in course of execution;

- it allows the establishment by articles of calculation and by causes of deviations form the standard costs of those effective during the execution of construction works;

- it uses only the calculation accounts existing in the accounts plan, by breaking down by analytical of the consumptions and deviations.

The standard cost method, as its name shows, operates with standards, the standard being defined as a "reference or a norm in measuring performance", and the standards established through the method of standard cost are physical or value dimensions with character of norm, established scientifically, based on certain modern method of registration, follow up and analysis of phenomena that take place in the patrimonial unit ${ }^{6}$. The application of the standard costs method requires the successive realization of the following works: calculation of standard cost and the calculus, follow up and reporting of deviations from standard costs; In order to respond to the management requirements in the control activity, the standard cost must be grounded on the knowledge of the real conditions of patrimonial unit.

For the calculus of value standards, our proposal is the use of the indicators provided by the National Institute of Statistics (INS), and the Romania's National Bank (BNR). Thus, if in 2009 the inflation rate was estimated to be $3.5 \%$, in reality reaching a percentage of $5.5 \%$, for 2010 the estimated percentage is of $2.76 \%{ }^{7}$, and taking into account that the index of consumption prices (IPC) was of $5.6 \%$ on the average in $2009^{8}$, we propose to consider a $6 \%$ index for the calculation of standards.

Because of the fluctuations registered in the world economy lately, but especially because of the economic crisis that has fully struck the Romanian economy, largely affecting the domain of constructions, and even if we were not witnessing all these economic troubles, we dare contradict the theory asserting that standard prices can be calculated as the average of acquisition prices of the previous periods (3-5 years), corrected by the predicted index of price growths caused by inflation, or other predictable factors.

Our proposal regarding this subject is that value standards should be set by taking into account the average period as being the period immediately prior to the elaboration of price standards (maximum 6 months), and their updating should be made in accordance with the trend of price growth registered in the reference period, but also with the inflation index announced for the period in which the construction works will be carried out.

The calculus of the standard cost with direct materials implies the anticipate calculation of the level of expenses corresponding to the execution of construction works. At the basis of determining the standard costs with the direct materials and considering the particular features of carrying out the execution of construction works, there lie, on the one hand, quantitative standards (physical) taken from the technical documentation called works estimates (concrete cubic metres), as well as the price standards, representing the standard acquisition costs of raw and consumable materials planned to be used in the production process. In our opinion, the appropriate element for the optimum follow up of consumption and deviations from present consumptions is the use of estimates by categories of works, estimates that are to be elaborated for each of the main stages of a construction, i.e. for foundations, brick walling, electric installations, plumbing and heating installations, finishing works. The establishment of standards implies the elaboration of the chart of the quantitative standard cost and the elaboration of the value unitary standards, and then, by combining the two situations, one will obtain the chart of standard cost:

\footnotetext{
5 R.H.Garrison, Management accounting. Concept for Planning, Control, Decision making, Fifth Edition, BPI/IRWIN, 1988, pag.383

${ }^{6}$ Briciu, Managerial accounting Theoretic and practical aspects, Economic Publishing House, Bucharest, 2006, pag. 170

${ }^{7}$ www.insse.ro, 21.02.2009

8 www.bnro.ro, 24.02.2009
} 
Table no. 1. List of value standards - Estimate of works - Foundation

\begin{tabular}{|c|c|c|c|c|}
\hline No. & Raw materials and materials & $\begin{array}{c}\text { Quantitative } \\
\text { standard }\end{array}$ & $\begin{array}{c}\text { Value } \\
\text { unitary } \\
\text { standard } \\
\text {-lei- }\end{array}$ & $\begin{array}{c}\text { Value } \\
\text { standard } \\
\text {-lei- }\end{array}$ \\
\hline 01 & $\begin{array}{c}\text { Beech log cls C, w=50mm, } \\
\mathrm{K}=2-5 \mathrm{~m}, \mathrm{~s} 8689\end{array}$ & $0.006 \mathrm{~m}^{3}$ & 948 & 5.69 \\
\hline 02 & $\begin{array}{c}\text { Long beech boards, cls A, } \\
\text { w=40mm, L=18.5 m, st8 }\end{array}$ & $0.001 \mathrm{~m}^{3}$ & 1615 & 1.62 \\
\hline 03 & $\begin{array}{c}\text { Conic head nails type 13x80 } \\
\text { o134s 2111 }\end{array}$ & $0.077 \mathrm{~m}^{3}$ & 8 & 0.62 \\
\hline 04 & $\begin{array}{c}\text { Beech round wood, 1 min, 1, d } \\
\text { under min 18 cm s434 }\end{array}$ & $0.003 \mathrm{~m}^{3}$ & 363 & 1.09 \\
\hline 05 & $\begin{array}{c}\text { Steel staples for wooden } \\
\text { constr., w=65-90mm, 1.200-30 }\end{array}$ & $0.021 \mathrm{~kg}^{-1}$ & 14 & 0.3 \\
\hline 06 & $\begin{array}{c}\text { Cement concrete b 200 STAS } \\
3622\end{array}$ & $17.990 \mathrm{~m}^{3}$ & 419 & 7537.81 \\
\hline 07 & Industrial water & $1.101 \mathrm{~m}^{3}$ & 1 & 1.101 \\
\hline \multicolumn{2}{|c|}{ TOTAL } & & 7548.23 \\
\hline
\end{tabular}

The calculation of standard cost with the direct labour. The standard cost with direct labour is determined based on labour standards expressed in time norms for each technological operation and based on wages tariffs corresponding to the qualification necessary for the execution of these operations, in other words, one considers the time standards and standard wages tariffs. The time standards are established based on statistic observation, careful and rigorous measurements of the execution mode of production, considering the technical conditions of their execution. The wages tariffs are set based on personnel qualification, the wages tariffs also including the contributions calculated on wages, according to the legislation in vigour, as well as the indemnities due by the company for legal leaves of absence or bonuses for the special labour conditions. The document centralising the data regarding the direct labour necessary in the execution of construction works is, similarly with the case of raw materials and other materials, the general estimate of works. The process of elaborating the chart of standard cost for the direct labour is identical with that of direct materials, finalised with the elaboration of the standard cost chart with direct labour.

Elaboration of standard calculations for the transport expenditure and equipment expenditure. In this stage we shall separately calculate the standards for transport and the standards for equipment. Thus, for the calculation of value standards of expenses with the transport of direct materials, we shall set the standards for ton $/ \mathrm{km}$ and for the unitary transport price afferent for ton $/ \mathrm{km}$. In setting the standards afferent to the equipment directly involved in the process of execution of construction works, we shall establish two standards and the material standard, hours of operation/piece of equipment, and the value standard afferent to one our of operation.

Elaboration of the standard calculations for the indirect production expenditure takes into account their structure, i.e. the inclusion of expenditure for the upkeep and operation of equipment, the general expenditure, that, added to the standard for direct materials and labour, constitutes the standard of production cost for a certain object of calculation, in the case of execution of construction works, the object of calculation is the construction in se.

The elaboration of the standard calculations for the indirect expenditure supposes the organisation of administration accounting by inscribing these expenses into the calculation item "Indirect production expenses", and their calculation is done through the elaboration of budgets for standard overheads. The elaboration of budgets for standard overheads must consider the separation of variable expenses from the fixed ones, the budget of fixed expenses comprising the standard overheads calculated for a single volume of productive activity (the building site for the work X), considered to be unchanged, and the flexible expenditure budget comprises the overheads of the building site for which it is elaborated in relation with different volumes and degrees of activity adopted as standard for the following year. As for the elaboration of the Budget of general administration general expenditure, it comprises the expenses with wages and their accessories for the administration and management personnel, office supplies, lighting expenditure, heating and other expenses of this type 
afferent to the administration and management offices, in general all the expenditure related to the administrative and management personnel of the company.

The calculation with the standard cost aims at elaborating the chart of total standard cost (table no. 2):

Table no. 2. Chart of standard costs valid for 2010

- Estimate per categories of works - Foundation

\begin{tabular}{|c|c|c|c|c|}
\hline No. & $\begin{array}{c}\text { Beech } \log \mathrm{cls} \mathrm{C}, \mathrm{w}=50 \mathrm{~mm} \text {, } \\
\mathrm{K}=2.5 \mathrm{~m}, \mathrm{~s} 8689\end{array}$ & $\begin{array}{l}\text { Quantitative } \\
\text { standard } \\
0.006 \mathrm{~m}^{3}\end{array}$ & $\begin{array}{l}\text { Value } \\
\text { unitary } \\
\text { standard } \\
\text {-1ei- } \\
948\end{array}$ & $\begin{array}{l}\text { V alue } \\
\text { standard } \\
\text {-lei- } \\
5.69\end{array}$ \\
\hline 02 & $\begin{array}{l}\text { Long beech boards, cls } A, \\
w=40 \mathrm{~mm}, L=18-4 \mathrm{~m} \text {, st }\end{array}$ & $0.001 \mathrm{~m}^{3}$ & 1615 & 1.62 \\
\hline 03 & $\begin{array}{c}\text { Conic head nails type } 13 \times 80 \\
\text { o134s } 2111\end{array}$ & $0.077 \mathrm{~m}^{3}$ & 8 & 0.62 \\
\hline 04 & $\begin{array}{l}\text { Beech round wood, } 1 \text { min, } 1, \mathrm{~d} \\
\text { under min } 18 \mathrm{~cm} \mathrm{s434}\end{array}$ & $0.003 \mathrm{~m}^{3}$ & 363 & 1.09 \\
\hline 05 & $\begin{array}{c}\text { Steel staples for wooden } \\
\text { constr., w }=65-90 \mathrm{~mm}, 1.200-30\end{array}$ & $0.021 \mathrm{~kg}$ & 14 & 0.03 \\
\hline 06 & $\begin{array}{c}\text { Cement concrete b } 200 \text { STAS } \\
3622\end{array}$ & $17.990 \mathrm{~m}^{3}$ & 419 & 7357.81 \\
\hline 07 & Industrial water & $1.101 \mathrm{~m}^{3}$ & 1 & 1.101 \\
\hline I & TOTAL M & TERIALS & & 7548.23 \\
\hline 01 & $\begin{array}{l}\text { Manual digging in limited spaces } \\
\text { under } 1 \mathrm{~m} \text { with supporting and } \\
\text { manual disposal in earth with } \\
\text { natural humidity at the depth of } 0 \text { - } \\
15 \mathrm{~m} \text { t. middle }\end{array}$ & 35 hours & 13.53 & 473.55 \\
\hline 02 & $\begin{array}{l}\text { Manual digging in limited spaces } \\
\text { under } 1 \mathrm{~m} \text { with supporting and } \\
\text { manual disposal in earth with } \\
\text { natural humidity at the depth of } \\
15 \text {-m t. middle }\end{array}$ & 46 hours & 13.53 & 622.38 \\
\hline 03 & 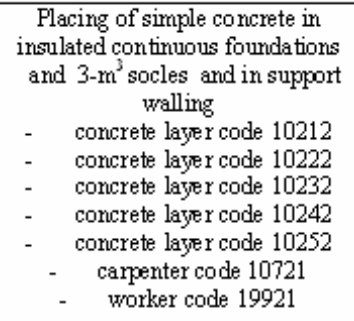 & $\begin{array}{c}7 \\
11 \\
5 \\
10 \\
10 \\
19 \\
35\end{array}$ & $\begin{array}{l}14.84 \\
15.75 \\
16.76 \\
18.27 \\
20.19 \\
15.44 \\
13.52\end{array}$ & $\begin{array}{c}103.88 \\
173.25 \\
838 \\
182.7 \\
201.9 \\
231.6 \\
513.76\end{array}$ \\
\hline 03 & $\begin{array}{c}\text { Placing of simple concrete in } \\
\text { radial continuous foundations and } \\
\text { walls under the ze ro level of the } \\
\text { constr., } 30 \text {-cm thick } \\
\text { - } \quad \text { concrete layer code } 10212 \\
\text { - } \quad \text { concrete layer code } 10222 \\
\text { - } \quad \text { concrete layer code } 10232 \\
\text { - concrete layer code } 10242 \\
\text { - concrete layer code } 10252 \\
\text { - } \quad \text { carpenter code } 10721 \\
\text { - } \quad \text { worker code } 19921\end{array}$ & $\begin{array}{c}7 \\
13 \\
6 \\
11 \\
11 \\
16 \\
42\end{array}$ & $\begin{array}{l}14.84 \\
15.75 \\
16.76 \\
18.27 \\
20.19 \\
15.44 \\
13.52\end{array}$ & $\begin{array}{l}103.88 \\
204.75 \\
100.56 \\
200.97 \\
222.09 \\
247.04 \\
567.84\end{array}$ \\
\hline II & \multicolumn{3}{|c|}{ TOTAL LABOUR } & 4233.95 \\
\hline 01 & Truck - m etal structures & 0.05 & 177 & 8.85 \\
\hline 02 & $\begin{array}{c}\text { Truck - wood wooden } \\
\text { structures }\end{array}$ & 0.07 & 208 & 14.56 \\
\hline 03 & Truck - building m aterials & 1.39 & 234 & 325.26 \\
\hline
\end{tabular}

The following stage in the application of the method of standard cost is the establishment of the deviations from the standard set in the first part. The total standard costs of the planned execution of works are considered normal costs that should be equal to those effectively realised, of the works 
structure of execution, the specific consumptions of materials, labour, standard prices and tariffs, as well as indirect costs would be identical with those stipulated in the calculation of standards. In reality there occur a series of perturbing factors that trigger the apparition of difference between standard and effective costs. These differences, called "deviations", can be calculated and highlighted by types of deviations, by stages of execution, by places and causes and promptly presented to the responsible factors in view of making the afferent decisions. Similarly with the case of standards determination, the establishment of deviations is done by the main elements comprised in the calculation of standards, i.e.: raw materials and materials, direct labour, transport and direct equipment, indirect expenses.

Table no. 3. Chart of standard costs valid for 2010 - Estimate per categories of works - Foundation

\begin{tabular}{|c|c|c|c|c|}
\hline No. & $\begin{array}{c}\text { Beech } \log \mathrm{cls} \mathrm{C}, \mathrm{w}=50 \mathrm{~mm}, \\
\mathrm{~K}=2.5 \mathrm{~m}, \mathrm{~s} 8689\end{array}$ & $\begin{array}{l}\text { Quantitative } \\
\text { standard } \\
0.006 \mathrm{~m}^{3}\end{array}$ & $\begin{array}{l}\text { Value } \\
\text { unitary } \\
\text { standard } \\
-1 \text { ei- } \\
948\end{array}$ & $\begin{array}{c}\text { V alue } \\
\text { standard } \\
\text {-lei- } \\
5.69\end{array}$ \\
\hline 02 & $\begin{array}{l}\text { Long beech boards, c1s } A \text {, } \\
w=40 \mathrm{~mm}, L=18-4 \mathrm{~m} \text {, st }\end{array}$ & $0.001 \mathrm{~m}^{3}$ & 1615 & 1.62 \\
\hline 03 & $\begin{array}{c}\text { Conic head nails type } 13 \times 80 \\
0134 \mathrm{~s} 2111\end{array}$ & $0.077 \mathrm{~m}^{3}$ & 8 & 0.62 \\
\hline 04 & $\begin{array}{l}\text { Beech round wood, } 1 \min , 1, \mathrm{~d} \\
\text { under } \min 18 \mathrm{~cm} s 434\end{array}$ & $0.003 \mathrm{~m}^{3}$ & 363 & 1.09 \\
\hline 05 & $\begin{array}{l}\text { Steel staples for wooden } \\
\text { constr., w=65-90mm, } 1.200-30\end{array}$ & $0.021 \mathrm{~kg}$ & 14 & 0.3 \\
\hline 06 & $\begin{array}{l}\text { Cement concrete b } 200 \text { STAS } \\
3622\end{array}$ & $17.990 \mathrm{~m}^{3}$ & 419 & 7537.81 \\
\hline 07 & Industrial water & $1.101 \mathrm{~m}^{3}$ & 1 & 1.101 \\
\hline I & TOTAL MA & ERIALS & & 7548.23 \\
\hline 01 & $\begin{array}{l}\text { Manual digging in limited spaces } \\
\text { under } 1 \mathrm{~m} \text { with supporting and } \\
\text { manual disposal in earth with } \\
\text { natural humidity at the depth of } 0 \text { - } \\
15 \mathrm{mt} \text {. middle }\end{array}$ & 35 hours & 13.53 & 473.55 \\
\hline 02 & $\begin{array}{l}\text { Manual digging in limited spaces } \\
\text { under } 1 \mathrm{~m} \text { with supporting and } \\
\text { manual disposal in earth with } \\
\text { natural humidity at the depth of } \\
15 \text {-m t. middle }\end{array}$ & 46 hours & 13.53 & 622.38 \\
\hline 03 & $\begin{array}{c}\text { Placing of simple concrete in } \\
\text { insulated continuous foundations } \\
\text { and 3-m socles and in support } \\
\text { walling } \\
\text { - concre te layer code } 10212 \\
\text { - concrete layer code } 10222 \\
\text { - concrete layer code } 10232 \\
\text { - concrete layer code } 10242 \\
\text { - concrete layer code } 10252 \\
\text { - carpenter code } 10721 \\
\text { - worker code } 19921\end{array}$ & $\begin{array}{c}7 \\
11 \\
5 \\
10 \\
10 \\
19 \\
35\end{array}$ & $\begin{array}{l}14.84 \\
15.75 \\
16.76 \\
18.27 \\
20.19 \\
15.44 \\
13.52\end{array}$ & $\begin{array}{c}103.88 \\
173.25 \\
83.8 \\
182.7 \\
201.9 \\
231.6 \\
513.76\end{array}$ \\
\hline 03 & $\begin{array}{l}\text { Placing of simple concrete in } \\
\text { radial continuous foundations and } \\
\text { walls under the zero level of the } \\
\text { constr., 30-cm thick } \\
\text { - concrete layer code } 10212 \\
\text { - } \quad \text { concrete layer code } 10222 \\
\text { - concrete layer code } 10232 \\
\text { - } \quad \text { concrete layer code } 10242 \\
\text { - concrete layer code } 10252 \\
\text { - carpenter code } 10721 \\
\text { - worker code } 19921\end{array}$ & $\begin{array}{c}7 \\
13 \\
6 \\
11 \\
11 \\
16 \\
42 \\
\end{array}$ & $\begin{array}{l}14.84 \\
15.75 \\
16.76 \\
18.27 \\
20.19 \\
15.44 \\
13.52 \\
\end{array}$ & $\begin{array}{l}103.88 \\
204.75 \\
100.56 \\
200.97 \\
222.09 \\
247.04 \\
567.84 \\
\end{array}$ \\
\hline II & \multicolumn{3}{|c|}{ TOTAL LABOUR } & 4233.95 \\
\hline 01 & Truck - metal structures & 0.05 & 177 & 8.85 \\
\hline 02 & $\begin{array}{c}\text { Truck - wood, wooden } \\
\text { structures }\end{array}$ & 0.07 & 208 & 14.56 \\
\hline 03 & Truck - building m aterials & 1.39 & 234 & 325.26 \\
\hline
\end{tabular}

The deviations from the standard cost with direct materials occur as a result of the registration of consumptions different from those taken into account when calculating the standard cost or as a result of acquisition prices different form the standard ones. The deviations afferent raw materials and materials monitor two situations. Deviations from the standard consumptions and the deviations from the standard costs. The situation of deviations are inscribed periodically, mainly at small period of time, in the "List of deviations form the standard cost" (table no.3), and at the end of the month 
the are centralised in the Report regarding the deviations form the standard cost for direct materials" (table n o. 4).

Table no. 4. List of deviations from the standard cost for direct materials Foundation

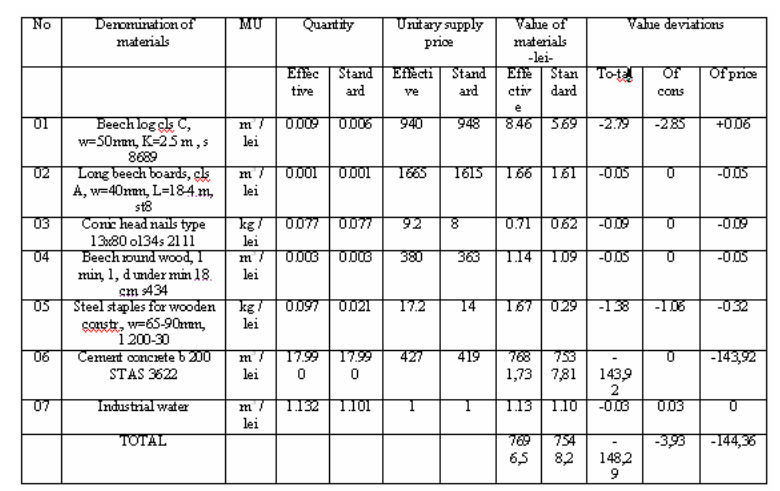

Table no. 5. Report regarding the deviation from the standard cost for direct materials

\begin{tabular}{|c|c|c|c|c|c|c|}
\hline \multirow[t]{2}{*}{ No } & \multirow[t]{2}{*}{ Denomination of order } & \multicolumn{3}{|c|}{ Vahe of materials } & \multicolumn{2}{|c|}{ Deviations } \\
\hline & & Effective & Standard & Total & $\begin{array}{l}\text { Cont } \\
\text { sump. }\end{array}$ & Frice \\
\hline 01 & $\begin{array}{c}\text { Repari work - over-storeving / } \\
\text { foundation }\end{array}$ & 76965 & 754821 & -148.29 & -393 & -144.36 \\
\hline & TOTAL & 76965 & 754821 & -148.29 & -393 & -144.36 \\
\hline
\end{tabular}

The deviations from the standard cost with direct labour. The establishment and analysis of deviations from the standard expenses with direct wages, including the contribution to the afferent social insurance funds and social security fund is an important issue that must be solved during the production process. For the prompt establishment of deviations, the administration accounting and cost calculation must be organised so that it could assure through systematic registration, comparison of labour standard costs with the effective one. The institutions elaborated for the follow up and analysis of deviations are the same as in the case of deviations with raw materials and direct materials.

The deviations from the standard costs with direct transport and equipment. Like in the case of direct materials and labour, we shall calculate the deviations form standard costs with equipment and direct transport afferent to foundation. The calculus of these deviations is required because, unlike other domains, where the production cost is calculated, being singled out separately, both in the general estimate and in the calculation estimates by objects.

Moreover, both for transport and for direct equipment one draws up extracts highlighting the total consumption for both calculation objects, but also the afferent unitary value. The values written down in these extract of transport, and equipment extracts, represent the standard of the respective work, any excess or economy from this value representing the positive of negative deviations, according to the situation.

The deviations from the indirect standard costs. The indirect costs contain both variable costs (considered proportional with the volume of activity of the centre), as well as fixed costs. They are comprised both in the calculation of standard cost per product (chart of standard cost), as well as in the determination of standard costs afferent to each construction stage according to the estimates per categories of works. The budgetary control of indirect costs must analyse both the influence of the falling within the budgetary stipulations, and the influence triggered by the degree of utilisation of the production of capacity and the efficiency obtained from the consumption of indirect factors afferent to the execution of works.

This type of deviations can be grouped in: 
- the deviations from the change of the volume of indirect expenses - they can be deviations from the actual budget or deviations from the recalculated budget. The budget of indirect standard costs is elaborated for a volume of standard activity, expressed in natural measurement units that represent in fact the connection factor (of causality) between the indirect costs to realise and the effectively executed works. In most cases one prefers as measuring unit the hour of direct labour. The total deviation from the initial standard budget as it does not take into account the variation of the volume of activity. At a reduced volume of activity with effectively smaller indirect costs we reach the conclusion that the total deviation is favourable, although the indirect costs for each site / stage can be much higher that the distributed standard share. Like in the case of direct costs it is necessary to recalculate the initial budget in accordance with the effectively executed works. This budget considered "admissible" comprises the standard costs afferent to the works realised in standard efficiency.

- deviations from the non-use of the standard capacity of time - they are caused by the underuse or overuse of the production capacity expressed through the volume of activity in labour units, and expresses the volume of unabsorbed or overabsorbed standard fixed costs, depending on the volume of activity realised, in comparison with the standard activity. It was found that if the effective activity is superior to that standard one, it will absorb a supraunitary share of fixed costs, or a subunitary share in the reversed situation.

- efficiency deviations - they are triggered by the use of a different quantity of work for the realisation of a production unit compared to the standard quantity.

\section{Conclusions}

In the present paper we attempted to underline the importance of the constructions domain in the national economy and not only, but we have especially tried to launch an alarm signal on the fact that, although the income from the field of constructions constitutes an important share of the national and EU's GDP, this domain remained in the rear of Romania's alignment to the European standards. The economic and social evolution is visible in constructions as regards the materials used, the labour executed, the specialisation of workers, in fact the alignment is visible in all the components of the execution of works in construction, less in the economic-financial legislation. We think that, considering the century of speed we live in and the advance in technology, it is inadmissible that, in the field of constructions, one should use lists o materials from the " 80 s, that the legislation in the field should not provide clear norms of elaboration of estimates of works. On the other hand, we think it necessary to also criticise the companies where we conducted our survey. First of all, the registration of expenses in view of calculating the cost is not detailed by direct and indirect expenditure, being practically impossible to exactly determine the share of the indirect expenditure afferent of the built object. Another issue we encountered is related to the structuring of the estimates of works. Then the use of the classic calculation methods are no longer necessary because we are no longer interested in the centralised production of constructions, the unanimous interest being to obtain profit and, so that this thing may be possible, we must find in due time the deviations occurred, to find the causes having led to their apparition precisely in order to avoid them in the future, and thus to reduce the uneconomical expenses. As the method by orders, method used at present in the field of construction, does not give us the possibility to see the deviations in time for affecting the current result, but by applying this method the result is deformed through unjustifiable passing of deviations to the deviations belonging to another period of administration, we consider that the application of the standard cost method, in the single standard cost variant, would led to the simplification of the calculation, to the clarification in time of deviations and causes having led to their occurrence, but the most important thing would lead to the correct determination of the result of the period.

\section{Bibliography}

1. Briciu, Managerial accounting. Theoretic and practical aspects, Economic Publishing House, Bucharest, 2006, pag. 170 


\section{Studies and Scientific Researches - Economic Edition, no. 15, 2010}

2. R.H.Garrison, Management accounting. Concept for Planning, Control, Decision making, Fifth Edition, BPI/IRWIN, 1988, pag.383

3. www.insse.ro, 21.02.2009

4. www.sfin.ro, 21.02.2009

5. www.reportereconomic.ro , 20.02.2009

6. www.epp.eurostat.ec.europa.eu, 17.02.2009

7. www.bnro.ro, 24.02.2009 